\title{
SALINIDADE DO SOLO E DESENVOLVIMENTO DO GIRASSOL SUBMETIDO À IRRIGAÇÃO COM ÁGUAS DE DIFERENTES QUALIDADES
}

\section{SOIL SALINITY AND SUNFLOWER DEVELOPMENT UNDER IRRIGATION WITH WATER OF DIFFERENT QUALITY}

Paulo Vitor Santa Rosa Silva.

Engenheiro Sanitarista e Ambiental, Universidade Federal do Recôncavo da Bahia. Mestrando em Engenharia Civil e Ambiental, Universidade Estadual de Feira de Santana. (paulovitor.srs@hotmail.com)

Patrícia dos Santos Nascimento.

Engenheira Agrônoma, Universidade Federal do Recôncavo da Bahia. Doutora em Agronomia (Irrigação e Drenagem), Universidade Estadual Paulista "Júlio de Mesquita Filho". Professora Auxiliar, Universidade Estadual de Feira de Santana. (patricianascimentouefs@gmail.com)

Submissão: 16 de Agosto de 2019

Aceite: 09 de Dezembro de 2019

\section{Resumo}

Em regiões de escassez hídrica, o uso da água de má qualidade, por vezes a única opção, tem sido uma alternativa para reduzir o elevado consumo de água de melhor qualidade na agricultura. Porém, o uso de águas ricas em sais, como os esgotos, pode causar danos à estrutura dos solos e à produção agrícola. Objetivou-se com esta pesquisa avaliar os impactos da salinidade de uma água de poço $\left(0,97 \mathrm{dS} \mathrm{m}^{-1}\right)$, do esgoto proveniente da Estação de Tratamento $\left(1,03 \mathrm{dS} \mathrm{m}^{-1}\right)$, esgoto de fossa séptica $\left(1,79 \mathrm{dS} \mathrm{m}^{-1}\right)$ e da água salina $\left(2,00 \mathrm{dS} \mathrm{m}^{-1}\right)$ no solo e no desenvolvimento da cultura do girassol. $O$ aumento da salinidade das águas de irrigação afetou, significativamente, os atributos químicos do solo, elevando os parâmetros condutividade elétrica, percentual de sódio trocável e o teor de sódio trocável do solo, porém, os parâmetros biométricos da cultura do girassol não foram afetados pela salinidade, exceto para os parâmetros massa seca e fresca das raízes, os quais geraram um crescimento com o aumento da salinidade. Constatou-se que o uso de águas residuárias promoveu médias superiores dos parâmetros: diâmetro do caule; diâmetro interno do capítulo; fitomassas frescas da parte aérea, do capítulo, e total; e fitomassas secas do capítulo e total, com relação às plantas irrigadas com os tratamentos com água de poço, esgoto da estação e água salina.

Palavras-chave: Sais, agricultura, esgoto.

\section{Abstract}

In water scarcity regions, the use of poor quality water, sometimes the only option, has been an alternative to reduce the high consumption of better quality water by agriculture. However, the use of salt-rich waters, such as sewage, can cause damage to soil structure and agricultural production. The objective of this research was to evaluate the salinity impacts of a well water $\left(0,97 \mathrm{dS} \mathrm{m}^{-1}\right)$, sewage from the treatment plant $(1,03 \mathrm{dS}$ $\left.\mathrm{m}^{-1}\right)$, septic tank sewage $\left(1,79 \mathrm{dS} \mathrm{m}^{-1}\right)$ and Saline Water $\left(2,00 \mathrm{dS} \mathrm{m}^{-1}\right)$ in the soil and development of Sunflower crop. Increasing salinity of irrigation waters significantly affected soil chemical attributes, increasing the electrical conductivity parameters, exchangeable sodium percentage and exchangeable sodium content, but the biometric parameters of sunflower crop were not affected by salinity, except for the parameters dry and fresh root mass, which generated growth with increasing salinity. It was found that the use of wastewater promoted higher means of the parameters: stem diameter; internal diameter of the chapter; fresh shoot, chapter, and total phytomassas; and chapter and total dried phytomasses in relation to plants irrigated with treatments with well water, sewage and saline water.

Keywords: Salts, agriculture, sewer.

\section{INTRODUÇÃO}

As atividades agrícolas exigem grandes áreas cultiváveis para irrigação, representando mais de $70 \%$ do consumo mundial (BORGHETTI et al., 2017) das reservas de água doce existentes.

Um dos principais inconvenientes do manejo 
inadequado da irrigação é a salinização dos solos. O uso de águas que, em sua composição química, apresentam sais dissolvidos, ao serem incorporados ao solo, causa danos ao mesmo, fato já evidenciado em várias regiões do planeta, principalmente nas regiões áridas e semiáridas, como o Nordeste brasileiro (MEDEIROS et al., 2016). Essa região, caracterizada pela escassez no suprimento de água, tanto em quantidade quanto em qualidade, é uma das regiões que mais sofre com problemas de salinização dos solos devido aos elevados índices de radiação solar, o que gera um grande potencial evapotranspirativo, além das baixas precipitações não possibilitarem uma lixiviação suficiente dos sais, o que eleva a concentração dos mesmos no solo (HOLANDA et al., 2016).

O semiárido brasileiro ocupa uma superfície de $69,2 \%$ da região Nordeste, e sempre apresentou problemas socioeconômicos que, em parte, estão associados à má distribuição das precipitações. Além dessa limitação, $85 \%$ da área encontram-se sobre rocha cristalina impermeável, onde é possível encontrar água subterrânea de má qualidade nas fraturas das rochas. Nessa região a escassez de água está associada à falta de garantia de oferta hídrica, uma vez que é assolada por períodos longos de seca e a maioria dos rios não é perene (PALÁCIO et al., 2004). Devido à escassez, as águas residuárias (esgoto) têm se mostrado uma alternativa de caráter sustentável para substituir volumes de água na irrigação nessas regiões, gerando diversos benefícios, como o direcionamento das águas de melhor qualidade para consumo humano, preservação da qualidade dos corpos hídricos e redução dos riscos de eutrofização, promoção da reciclagem dos nutrientes, além de reduzir o uso de adubos e fertilizantes nas atividades agrícolas devido ao alto conteúdo de nitrogênio, fósforo e, eventualmente, matéria orgânica (TELLES, 2011).

Apesar dos benefícios do reúso, a utilização de esgoto como água de irrigação não é uma prática isenta de riscos, uma vez que apresenta consideráveis concentrações de sódio, organismos patogênicos e contaminantes orgânicos. Esses compostos podem causar riscos de degradação da estrutura do solo, alterando suas propriedades químicas e físico-hídricas, como a obstrução do espaço poroso, além de apresentar riscos à saúde humana quando não manejados de forma correta, comprometendo a viabilidade da prática do reúso agrícola (LEAL, 2007).
Os sais presentes nos esgotos são adicionados à água através dos mais diversos usos domésticos e industriais, e sua concentração varia entre 100 e $800 \mathrm{mg} \mathrm{L}^{-1}$, e mesmo em concentrações relativamente baixas, os sais são suficientes para alterar a qualidade da água de aceitável para questionável, considerando seu uso para irrigação na agricultura (FEIGIN et al., 1991). A determinação da concentração de $\mathrm{Na}^{+}$é essencial devido às alterações causadas por esse sal nas propriedades do solo. Os efluentes possuem consideradas concentrações de sódio em sua composição, de 50 a $250 \mathrm{mg} \mathrm{L}^{-1}$, o que pode gerar um incremento da sodicidade no solo (BALKS et al., 1998).

A salinização em áreas irrigadas no semiárido do Nordeste brasileiro tem ocasionado alterações nas características físico-hídricas dos solos, devido à ação dispersiva dos sais sobre as partículas de solo, tornando-os compactos (RESENDE et al., 2014). A utilização de águas residuárias como fonte de irrigação, se utilizadas de forma indiscriminada, também pode afetar alguns atributos dos solos. Concentrações altas de sódio e baixa concentração de cálcio e magnésio podem causar obstrução do espaço poroso, reduzindo a infiltração de água no solo (PEDRERO et al., 2010).

Além dos efeitos sobre os solos, a salinidade também traz efeitos negativos para as plantas. A salinidade afeta as culturas de três formas: à medida que a concentração de sais no solo aumenta, aumenta-se também 0 potencial osmótico do solo; quanto mais salino for um solo, mais energia será gasta pelas plantas para absorver água e os elementos vitais para o seu desenvolvimento; e devido à toxicidade de elementos como boro, sódio, bicarbonatos e cloreto, ocasionam-se problemas fisiológicos para as culturas (BATISTA et al., 2002).

O princípio da sustentabilidade requer o não acúmulo de sais pela irrigação, que pode vir a causar danos aos solos cultivados, ou seja, o teor de sais pela água de irrigação deve ser igual ou menor do que a quantidade que pode ser exportada do sistema irrigado (JENSEN et al., 2001), portanto, o monitoramento dos parâmetros de qualidade das águas de irrigação se mostra essencial para avaliação dos impactos ambientais devido às atividades agrícolas (MOLOZZl et al., 2005).

Objetivou-se com o presente trabalho, identificar as alterações nas propriedades 
químicas do solo e no desenvolvimento da cultura do girassol devido às salinidades de águas de irrigação com diferentes qualidades. A boa adaptação do girassol aos diversos climas e regiões, sua importância econômica devido ao óleo extraído da semente, e a tolerância moderada à salinidade motivaram a seleção dessa cultura para a pesquisa. Além dos fatores citados, há também a questão da resistência da população com relação ao consumo de alimentos irrigados com esgoto, e como o girassol é uma cultura utilizada para ornamentação, se torna mais fácil a implantação e utilização dos esgotos como uma alternativa de água de irrigação para essa cultura.

\section{MATERIAL E MÉTODOS}

A pesquisa foi realizada na sede da Equipe de Estudos Ambientais (EEA) da Universidade Estadual de Feira de Santana (UEFS), no município de Feira de Santana, em campo aberto, como mostra a Figura 1. O município de Feira de Santana está localizado no semiárido do estado da Bahia com coordenadas geográficas $12^{\circ} 16^{\prime}$ 00 latitude sul e $38^{\circ} 58^{\prime} 00$ longitude oeste de Greenwich.

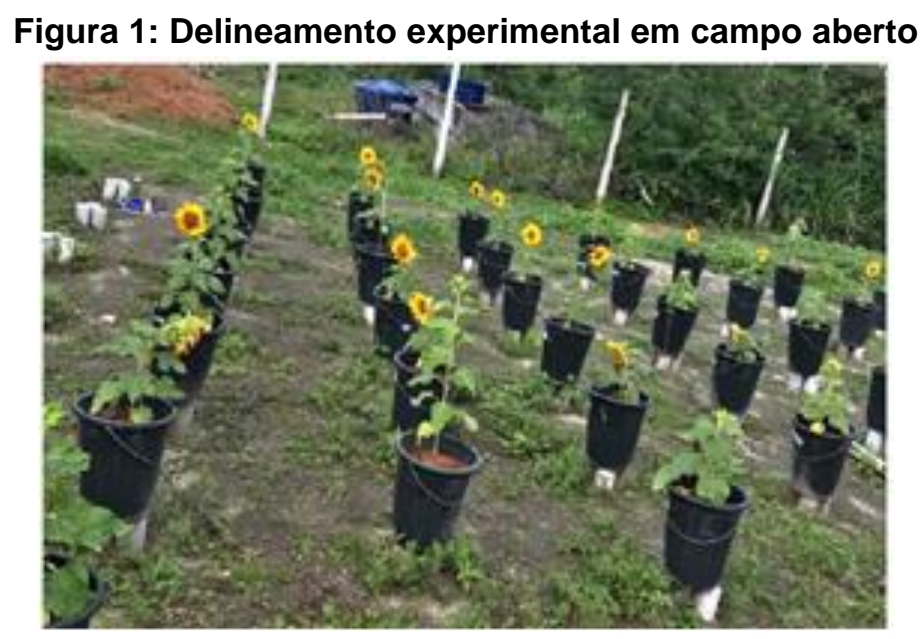

Fonte: Próprio Autor (2018).

O delineamento experimental utilizado foi 0 inteiramente casualizado, constando de 4 tratamentos e 6 repetições, totalizando 24 parcelas experimentais. Os tratamentos testados foram: AP - Água de poço (CE = 0,97 dS m-1); EE - Esgoto proveniente da Estação de Tratamento de Esgoto Jacuípe, da Empresa Baiana de Águas e Saneamento (EMBASA), no município de Feira de Santana-BA, onde foi aplicado apenas 0 tratamento preliminar $\left(\mathrm{CE}=1,03 \mathrm{dS} \mathrm{m}^{-1}\right)$; $\mathrm{EF}$ Esgoto de uma fossa séptica da EEA/UEFS (CE = $1,79 \mathrm{dS} \mathrm{m}^{-1}$ ); e AS - Água salina (obtida pela adição de $\mathrm{NaCl}$ comercial, $\mathrm{CE}=2,00 \mathrm{dS} \mathrm{m}^{-1}$ ).

A cultura utilizada foi o Girassol Anão de Jardim (Helianthus annus L.), sendo a propagação realizada por sementes em baldes, nos quais se desenvolveu ao longo de todo o experimento, irrigado diariamente com água de poço antes da aplicação dos tratamentos. A semeadura foi realizada no dia 13/10/2018, e 23 dias após a semeadura (DAS) começou-se a aplicar os tratamentos, no dia 05/11/2018, finalizando o ciclo no dia 31/12/2018.
O solo foi originado de um perfil proveniente do Campus da UEFS, coletado da camada 0 $150 \mathrm{~cm}$. O solo foi seco ao ar livre e posteriormente retiradas amostras para análises físicas e químicas. Após o solo ser seco ao ar, destorroado, peneirado em malha de $5 \mathrm{~mm}$ e acomodado nos baldes, foi iniciado o processo de saturação dos mesmos, com a água de poço, até que ocorresse o início da drenagem em cada vaso.

Para obtenção da condutividade elétrica desejada do tratamento $\mathrm{AS}$, adicionou-se $\mathrm{NaCl}$ comercial a água de poço da EEA. A quantidade de cloreto de sódio ( $\mathrm{Q} \mathrm{NaCl}$ ) utilizada no preparo da água foi determinada a partir da condutividade elétrica inicial da água, através da equação proposta por Richards (1954): Q NaCl (mg L-1) = 640 x (CEa desejada - CEa inicial), em que CEa é condutividade elétrica da água, em dS m-1.

A irrigação foi feita manualmente com o uso de recipientes graduados, sendo calculada em planilha de Excel, pelo método de PenmanMonteith-FAO para quantificação da 
evapotranspiração de referência (ETo), seguindo a metodologia de cálculo apresentada por Allen et al. (1998) para dados de evapotranspiração de hora em hora.

Para os dados de entrada da planilha, foram utilizados os fornecidos pela estação automática (INMET/DTEC) da UEFS, situada a menos de 80 metros da EEA, o que deu uma maior confiabilidade devido à proximidade da estação ao local do experimento.

Dos dados disponíveis da estação, foram utilizados os seguintes parâmetros: Temperatura Máxima e Mínima $\left({ }^{\circ} \mathrm{C}\right)$, Umidade Máxima e Mínima (\%), Pressão Atmosférica Máxima e Mínima (hPa), Velocidade do Vento $(\mathrm{m} / \mathrm{s})$, Radiação Solar $\left(\mathrm{KJ} / \mathrm{m}^{2}\right)$ e Precipitação $(\mathrm{mm})$. A partir desses dados, foram calculados os demais parâmetros essenciais para a realização do cálculo da evapotranspiração de referência, e tanto o cálculo da evapotranspiração como os parâmetros da equação foram baseados em Allen et al. (1998).

Os dados da estação automática são obtidos a cada hora, logo, foi obtida a cada hora uma evapotranspiração dada em $\mathrm{mm} / \mathrm{h}$. A evapotranspiração diária foi obtida calculando-se a somatória da evapotranspiração das $24 \mathrm{~h}$ anteriores ao horário da irrigação, ou seja, das $8 \mathrm{~h}$ da manhã do dia anterior ao da irrigação até às $7 \mathrm{~h}$ da manhã do dia da irrigação, visto que a irrigação foi realizada às $8 \mathrm{~h}$ da manhã ao longo de todo o experimento.

Obteve-se a evapotranspiração da cultura (ETc) pelo produto da evapotranspiração diária (ETo) com o Coeficiente da Cultura (Kc), ou seja, $\mathrm{ETc}=\mathrm{ETo} \times \mathrm{Kc}$, onde o $\mathrm{Kc}$ é predefinido para cada fase fenológica do Girassol (Fase I: Inicial, $\mathrm{Kc}=0,60$ para 28 dias; Fase II: Desenvolvimento Vegetativo, $\mathrm{Kc}=0,95$ para 15 dias; e Fase III: Floração, $\mathrm{Kc}=1,09$ para 27 dias), como recomendado pela FAO e citado em Cavalcante Junior et al. (2013). Para determinação do volume diário (Vd) de água de irrigação que cada balde irá receber, foi multiplicada a diferença entre a evapotranspiração da cultura (ETc) e a precipitação diária $(\mathrm{Pd})$ pela área superficial do balde $(A s B)$, ou seja, $V d=(E T c-P d) \times$ Asb. Nos dias em que a precipitação foi superior a evapotranspiração, não foi realizada a irrigação.

Efetuou-se a caracterização química das águas de irrigação pela metodologia sugerida pelo Standard Methods for the Examination of Water and Wastewater (APHA, 2005), bem como a do solo, pela metodologia de Silva (2009), para identificação das alterações das propriedades antes e após a aplicação dos tratamentos. Para a análise biométrica do girassol, foram analisados os seguintes parâmetros: altura da planta, diâmetro do caule, diâmetro interno e externo do capítulo, número de folhas e fitomassa fresca e seca, como indicado por Jardini et al. (2014) e Azevedo et al. (2016).

Os parâmetros altura de planta, diâmetro do caule e número de folhas foram medidos três vezes ao longo do ciclo, aos 40,60 e 80 dias após a semeadura (DAS).

Segundo Biscaro et al. (2008), o diâmetro do caule é um parâmetro importante no girassol, considerando que quanto maior o diâmetro do caule menor a vulnerabilidade ao acamamento, facilitando seu manejo, tratos culturais e colheita.

O estudo do parâmetro número de folhas é importante devido à sensibilidade desse órgão em meio salino, sofrendo redução em tamanho e número (MEDEIROS et al., 2011), provocada pela abscisão, em função da senescência precoce por conta da ação nociva das altas concentrações de sais nas águas de irrigação (TAIZ; ZEIGER, 2013).

Segundo Lobo e Grassi Filho (2007), o diâmetro do capítulo é importante parâmetro por implicar no número potencial de grãos, fator essencial na produtividade, e o DEC é um fator importante para o comércio de flores ornamentais.

Para análise da salinidade do solo, foram avaliados $\mathrm{o} \mathrm{pH}$, a condutividade elétrica do extrato de saturação, o teor de sódio e o percentual de sódio trocável, que segundo Richards (1954) são os parâmetros mais importantes para avaliação da salinidade do solo.

Os resultados obtidos foram submetidos à análise de variância (ANOVA), comparando os dados pelo Teste de Tukey ao nível de $5 \%$ de probabilidade, com a utilização dos programas computacionais de estatística Past e RStudio. Para análise dos dados dos coeficientes de variação, utilizou-se a classificação de Warrick e Nielsen (1980).

\section{RESULTADOS DE DISCUSSÃO}

As características químicas encontradas nas águas de irrigação utilizadas no experimento com o girassol estão apresentadas na Tabela 1.

O solo natural (SN) utilizado no experimento apresentou uma composição granulométrica de $20 \%$ para areia média, $31 \%$ de areia fina, $9 \%$ de 
silte e $40 \%$ de argila, sendo classificado como um solo argilo-arenoso. As características químicas do solo natural antes da aplicação dos tratamentos estão apresentadas na Tabela 2.

Segundo Richards (1954), para avaliação da salinidade do solo, os parâmetros mais importantes são o $\mathrm{pH}$, a condutividade elétrica, o teor de sódio e o percentual de sódio trocável. A Tabela 3 apresenta a estatística descritiva de tais parâmetros do solo antes e após a aplicação dos tratamentos.

Tabela 1: Características das águas de irrigação utilizadas no ciclo do girassol

\begin{tabular}{|c|c|c|c|c|}
\hline PARÂMETROS & AP & EE & EF & AS \\
\hline $\mathrm{pH}$ & 7,05 & 7,41 & 7,64 & 6,8 \\
\hline RAS & $18,13 \pm 0,65$ & $29,87 \pm 3,13$ & $20,62 \pm 2,06$ & $120,58 \pm 6,75$ \\
\hline Classificação pela RAS & $\begin{array}{c}0,97 \\
\text { S1 - Água com } \\
\text { baixa } \\
\text { concentração } \\
\text { de sódio }\end{array}$ & $\begin{array}{c}1,03 \\
\mathrm{~S} 1-\text { Água com } \\
\text { baixa } \\
\text { concentração de } \\
\text { sódio }\end{array}$ & $\begin{array}{l}1,79 \\
\text { S1 - Água com } \\
\text { baixa } \\
\text { concentração } \\
\text { de sódio }\end{array}$ & $\begin{array}{l}2,00 \\
\text { S4 - Água com } \\
\text { muito alta } \\
\text { concentração de } \\
\text { sódio }\end{array}$ \\
\hline Classificação pela CE & $\begin{array}{l}\text { C3 - Água com } \\
\text { alta salinidade }\end{array}$ & $\begin{array}{l}\text { C3 - Água com } \\
\text { alta salinidade }\end{array}$ & $\begin{array}{l}\text { C3 - Água com } \\
\text { alta salinidade }\end{array}$ & $\begin{array}{l}\text { C3 - Água com } \\
\text { alta salinidade }\end{array}$ \\
\hline Dureza/mg L-1 & $188,00 \pm 2,00$ & $82,00 \pm 5,29$ & $192,67 \pm 1,15$ & $37,33 \pm 4,16$ \\
\hline Alcalinidade/mg L-1 & $17,33 \pm 1,15$ & $330,67 \pm 4,62$ & $408,00 \pm 8,00$ & $20,67 \pm 1,15$ \\
\hline Cálcio/mg L-1 & $172,55 \pm 2,10$ & $75,57 \pm 5,29$ & $178,77 \pm 1,18$ & $30,84 \pm 4,16$ \\
\hline Magnésio/mg L-1 & $15,45 \pm 0,67$ & $6,43 \pm 0,13$ & $13,90 \pm 0,27$ & $6,49 \pm 0,21$ \\
\hline Sódio/mg L-1 & $175,80 \pm 6,22$ & $191,25 \pm 19,31$ & $202,36 \pm 20,70$ & $520,97 \pm 4,21$ \\
\hline Potássio/mg L-1 & $17,49 \pm 2,98$ & $28,93 \pm 6,25$ & $38,89 \pm 6,09$ & $34,30 \pm 4,76$ \\
\hline Cloreto/mg L-1 & $391,33 \pm 1,15$ & $149,33 \pm 4,62$ & $362,67 \pm 12,22$ & 660,00 \\
\hline Fósforo/mg L-1 & 0 & 10,40 & 7,40 & 0 \\
\hline Nitrogênio/mg L-1 & 0 & $140,00 \pm 28,00$ & $140,00 \pm 28,00$ & 0 \\
\hline $\mathrm{DBO} / \mathrm{mg} \mathrm{L}^{-1}$ & 0 & $260,00 \pm 70,00$ & $20,00 \pm 13,00$ & $4,00 \pm 3,61$ \\
\hline Sólidos Totais/mg L-1 & $806,67 \pm 64,29$ & $540,00 \pm 40,00$ & 1040,00 & $1230,00 \pm 90,00$ \\
\hline Sólidos Dissolvidos/mg L-1 & 800,00 & $466,67 \pm 202,32$ & 960,00 & $1150,00 \pm 10,00$ \\
\hline Sólidos Suspensos/mg L-1 & 0 & $123,55 \pm 6,65$ & 23,50 & 5,00 \\
\hline $\begin{array}{l}\text { Coliformes Totais } \\
\text { /NMP } 100 \mathrm{~mL}^{-1}\end{array}$ & $>23$ & $3,50 \times 10^{4}$ & $>1,60 \times 10^{8}$ & AUSENTE \\
\hline $\begin{array}{l}\text { Coliformes Fecais } \\
\text { /NMP } 100 \mathrm{~mL}^{-1}\end{array}$ & AUSENTE & $1,30 \times 10^{4}$ & $1,60 \times 10^{8}$ & AUSENTE \\
\hline
\end{tabular}

AP - Água de Poço; EE - Esgoto da Estação de Tratamento; EF - Esgoto da Fossa e AS - Água Salina; RAS Razão de Adsorção de Sódio, CE - Condutividade Elétrica. Fonte: Próprio Autor (2018).

Tabela 2: Características químicas do solo natural

\begin{tabular}{|c|c|c|c|c|c|c|}
\hline $\begin{array}{c}\mathrm{pH} \\
\text { (salinidade) }\end{array}$ & $\begin{array}{c}\mathrm{pH} \\
\text { (em água) }\end{array}$ & $\begin{array}{c}\mathrm{Na} \\
/ \mathrm{cmolc} \mathrm{dm}^{-3}\end{array}$ & $\begin{array}{c}\mathrm{K} \\
\text { /cmolc dm }{ }^{-3}\end{array}$ & $\begin{array}{c}\mathrm{Ca} \\
/ \mathrm{cmolc} \mathrm{dm}^{-3}\end{array}$ & $\begin{array}{c}\mathrm{Mg} \\
\text { /cmolc dm-3 }\end{array}$ & $\begin{array}{c}\mathrm{H}+\mathrm{Al} \\
/ \mathrm{cmolc} \mathrm{dm}^{-3}\end{array}$ \\
\hline 6,42 & 6,20 & 0,17 & 0,18 & 1,71 & 1,60 & 1,98 \\
\hline $\begin{array}{l}\text { Soma de } \\
\text { Bases } \\
\text { /cmolc dm }{ }^{-3}\end{array}$ & $\begin{array}{c}\text { Saturação } \\
\text { por Bases } \\
1 \%\end{array}$ & $\begin{array}{c}\text { Matéria } \\
\text { Orgânica } \\
/ \mathrm{g} \mathrm{Kg}^{-1}\end{array}$ & $\begin{array}{c}P \\
/ \mathrm{mg} \mathrm{dm}^{-3}\end{array}$ & $\begin{array}{c}\text { CTC } \\
/ \mathrm{cmolc} \mathrm{dm}^{-3}\end{array}$ & $\begin{array}{l}\text { PST } \\
/ \%\end{array}$ & $\begin{array}{l}\text { CEes } \\
/ \mathrm{dS} \mathrm{m}^{-1}\end{array}$ \\
\hline 3,66 & 65,00 & 6,00 & 6,00 & 5,64 & 3,01 & 0,87 \\
\hline
\end{tabular}


Tabela 3: Estatística descritiva para os dados de pH, condutividade elétrica do extrato de saturação (CEes), percentual de sódio trocável (PST) e teor de sódio trocável ( $\mathrm{Na}^{+}$) do solo antes e após a aplicação dos tratamentos

\begin{tabular}{ccccccc} 
& & $\mathrm{SN}$ & $\mathrm{SAP}$ & $\mathrm{SEE}$ & $\mathrm{SEF}$ & $\mathrm{SAS}$ \\
\hline $\mathrm{pH}$ & $\mu$ & $6,42 \mathrm{a}$ & $6,75 \mathrm{a}$ & $6,56 \mathrm{a}$ & $6,48 \mathrm{a}$ & $6,55 \mathrm{a}$ \\
& $\mathrm{CV} / \%$ & 0,70 & 1,96 & 1,91 & 2,10 & 1,99 \\
\hline $\mathrm{CEes} / \mathrm{dS} \mathrm{m}^{-1}$ & $\mu$ & $0,87 \mathrm{e}$ & $1,32 \mathrm{de}$ & $1,44 \mathrm{cde}$ & $1,88 \mathrm{bcd}$ & $4,01 \mathrm{a}$ \\
& $\mathrm{CV} / \%$ & 1,15 & 0,76 & 22,17 & 14,10 & 15,84 \\
\hline $\mathrm{PST} / \%$ & $\mu$ & $3,01 \mathrm{e}$ & $12,69 \mathrm{~d}$ & $16,81 \mathrm{~cd}$ & $18,59 \mathrm{bcd}$ & $29,84 \mathrm{a}$ \\
& $\mathrm{CV} / \%$ & 10,01 & 2,58 & 1,54 & 1,63 & 0,84 \\
\hline $\mathrm{Na}^{+} / \mathrm{cmolc}^{-3} \mathrm{dm}^{-3}$ & $\mu$ & $0,17 \mathrm{e}$ & $0,77 \mathrm{~d}$ & $0,93 \mathrm{~cd}$ & $1,14 \mathrm{bc}$ & $2,08 \mathrm{a}$ \\
& $\mathrm{CV} / \%$ & 12,34 & 42,03 & 16,28 & 16,05 & 10,26
\end{tabular}

SN - Solo Natural; SAP - Solo após aplicação da Água de Poço (0,97 dS m $\left.{ }^{-1}\right)$; SEE - Solo após aplicação do Esgoto da Estação de Tratamento $\left(1,03 \mathrm{dS} \mathrm{m} \mathrm{m}^{-1}\right)$; SEF - Solo após aplicação do Esgoto da Fossa (1,79 dS m $\left.{ }^{-1}\right)$; SAS - Solo após aplicação da Água Salina $\left(2,00 \mathrm{dS} \mathrm{m}^{-1}\right) ; \mu$ - média; CV coeficiente de variação. Médias seguidas de letras minúsculas na mesma linha não diferem estatisticamente pelo teste de Tukey a 5\%. Fonte: Próprio Autor (2018).

Figura 2: Regressão para os valores médios do $\mathrm{pH}$ (a), condutividade elétrica do extrato de saturação (b), do percentual (c) e do teor de sódio trocável (d) do solo com relação a condutividade elétrica das águas dos diferentes tratamentos aplicados, com coeficiente de determinação
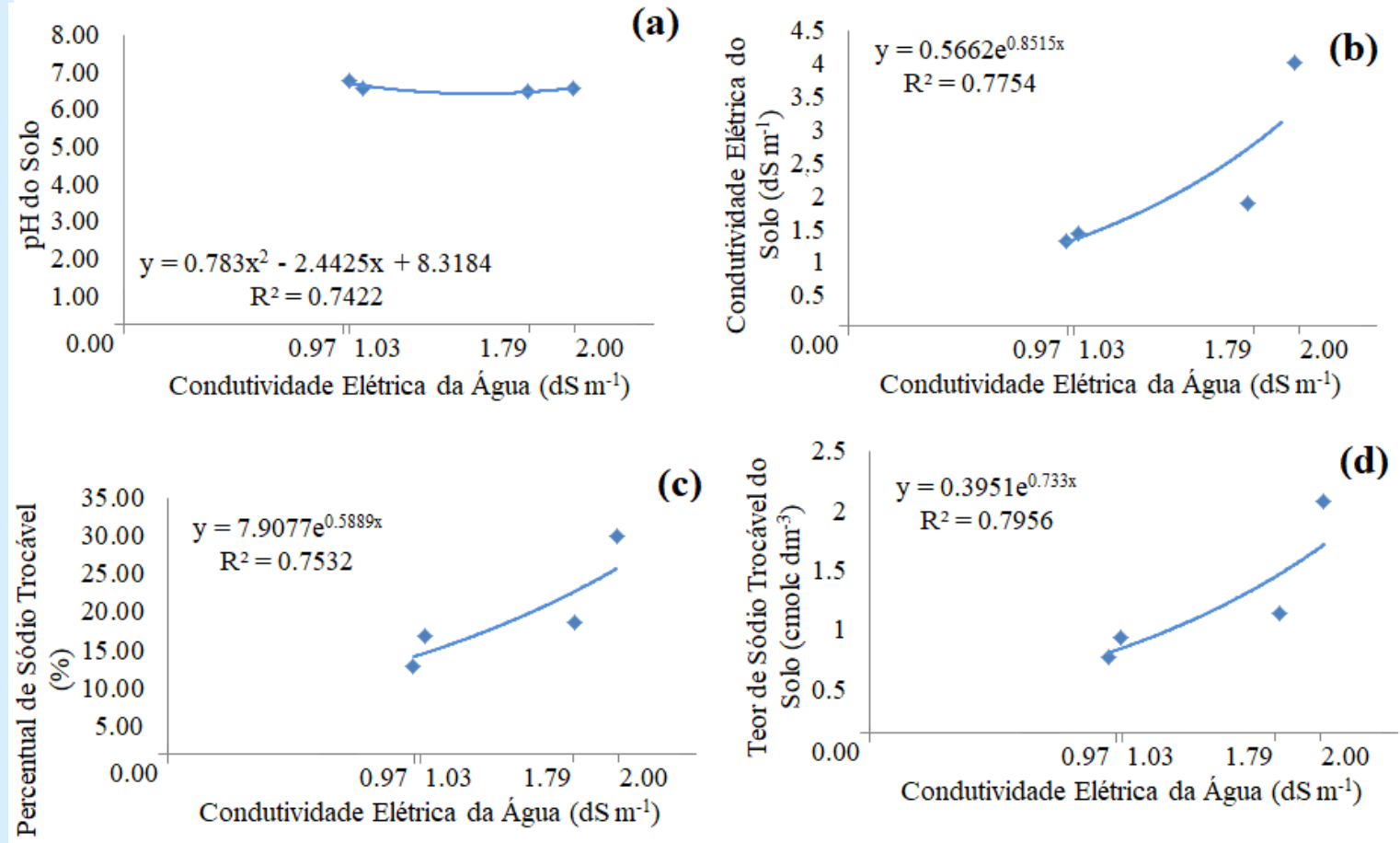

Água de Poço $\left(0,97 \mathrm{dS} \mathrm{m}^{-1}\right)$; Esgoto da Estação de Tratamento (1,03 $\left.\mathrm{dS} \mathrm{m}^{-1}\right)$; Esgoto da Fossa $\left(1,79 \mathrm{dS} \mathrm{m}^{-1}\right) \mathrm{e}$ Água Salina $\left(2,00 \mathrm{dS}^{-1}\right)$. Fonte: Próprio Autor (2018).

A análise de variância não apresentou diferença significativa entre o $\mathrm{pH}$ do solo antes e após a aplicação dos tratamentos, como mostra a Tabela 1, e analisando os resultados dos coeficientes de variação, verifica-se uma baixa variação para o $\mathrm{pH}$. A condutividade elétrica das águas dos diferentes tratamentos não afetou o pH do solo, que, após a aplicação dos tratamentos, manteve-se na amplitude entre 6,48 a 6,75, sendo 0 solo natural $(\mathrm{SN})$ com $0 \quad \mathrm{pH}$ 
correspondente a 6,42, não apresentando uma tendência de crescimento ou decrescimento, como mostra a Figura 2 (a).

Dois fatores podem ter contribuído para a não variação do $\mathrm{pH}$ do solo: na composição química das águas de irrigação, as quantidades de $\mathrm{Na}^{+}$e $\mathrm{Cl}^{-}$são maiores que os valores de $\mathrm{HCO}_{3}{ }^{-}$ (alcalinidade), prevalecendo a neutralidade do $\mathrm{NaCl}$ com relação ao $\mathrm{pH}$, impedindo a hidrólise do $\mathrm{Na}^{+}$que pode elevar $\mathrm{o} \mathrm{pH}$, e não existindo concentrações consideráveis de $\mathrm{Na}_{2} \mathrm{CO}_{3}$ e com o $\mathrm{H}_{2} \mathrm{O}$, podem ocorrer reações alcalinas que podem resultar no $\mathrm{pH}$ de até 10 (TAN, 1982); outro fator está associado ao baixo teor de matéria orgânica presente nas águas utilizadas, uma vez que, em águas com elevado teor de matéria orgânica, durante a degradação da mesma, há a produção de $\mathrm{CO}_{2}$ e liberação de ácidos orgânicos que podem vir a acidificar o solo, diminuindo o $\mathrm{pH}$ do mesmo (BOUWER, 2000).

Tal comportamento também foi evidenciado por Gomes (2016), Mourão (2014), Andrade Filho et al. (2013) e Porto Filho et al. (2011) que, ao analisarem a salinidade do solo das áreas cultivadas, não observaram variação significativa do $\mathrm{pH}$ do solo durante e após a irrigação.

Com relação ao parâmetro condutividade elétrica do solo, a análise de variância apresentou significância entre o solo irrigado com água salina (SAS) e o solo irrigado com esgoto da fossa (SEF) com relação ao SN, sendo que a CEes do solo irrigado com água salina obteve o maior valor com relação aos outros tratamentos, correspondendo a um aumento de $361 \%$, e um aumento de $116 \%$ para o solo que recebeu 0 esgoto da fossa. Os solos irrigados com água de poço e com o esgoto da estação proporcionaram um aumento na condutividade do solo de 52 e $66 \%$, respectivamente. Analisando-se os resultados dos coeficientes de variação, verificase uma baixa variação para a CEes do SN e do solo irrigado com água de poço (SAP), e média variação para a CEes dos solos SAS, SEF e do solo irrigado com o esgoto da estação de tratamento (SEE).

A partir da Tabela 3, observa-se que a condutividade elétrica do solo aumentou à medida que se aumentou a condutividade elétrica das águas dos tratamentos, sendo a regressão exponencial o modelo que mais se ajustou aos resultados, como mostra a Figura 2 (b). Comportamento semelhante também observado por Holanda Filho et al. (2011), Lima Neto et al. (2015) e Cavalcante et al. (2010), os quais constataram um aumento significativo da condutividade elétrica do extrato de saturação do solo e um aumento linear em função da salinidade da água de irrigação.

O aumento da salinidade do solo após o uso de águas salinas, mantendo-se as mesmas condições de manejo da irrigação, é esperado, uma vez que, quanto maior a condutividade elétrica da água para um mesmo volume aplicado, mais sais são incrementados no solo (PORTO FILHO et al., 2011).

De acordo com a Figura 2 (c), observa-se uma tendência crescente do percentual de sódio trocável do solo à medida que se aumenta a condutividade elétrica da água. Comportamento semelhante foi observado por Costa et al. (2013). Nascimento e Fidelis Filho (2015) e Oliveira et al. (2013) também verificaram que o percentual de sódio trocável do solo foi elevado após a irrigação, sendo que, em ambos, ficou constatado que a produtividade média da cultura mais baixa correspondeu aos solos com os maiores PST.

A análise de variância mostrou que 0 aumento do percentual de sódio trocável (PST) foi significativo, com relação ao solo natural, em todos os solos que receberam os tratamentos, como mostra a Tabela 3; destaque para o tratamento com água salina, que aumentou em $891 \%$ o PST e que alterou a condição do solo natural de Não Sódico para Fortemente Sódico. Os tratamentos com água de poço, esgoto da estação e da fossa aumentaram o PST do solo natural para 322, 458 e 518\%, respectivamente, alterando a condição do solo natural para Mediamente Sódicos, classificação proposta por Massoud (1971) para avaliação do grau de sodicidade do solo. Com relação à salinidade dos solos, segundo classificação de Richards (1954), baseada no $\mathrm{pH}$, na CEes e no PST, o tratamento com água de poço não alterou a condição do solo natural, que foi classificado como não sódico e não salino. Já as águas residuárias e a água salina alteraram para um solo salino e um solo salino-sódico, respectivamente.

Com relação ao parâmetro teor de sódio trocável no solo, observam-se concentrações significativas deste elemento em todos os solos, quando comparados ao solo natural, como mostra a Tabela 3, constatando-se um aumento de 353\% para o solo que recebeu água de poço, 447\% para o solo do tratamento esgoto da estação e $571 \%$ para o solo que recebeu o esgoto da fossa. Já o solo que recebeu a água salina obteve as maiores concentrações de sódio trocável no solo, 
o que proporcionou um aumento de $1124 \%$. Comportamento semelhante aos resultados obtidos na presente pesquisa também foi constatado por Holanda Filho et al. (2011) e Nascimento e Fidelis Filho (2015) que, ao aplicarem água salina e água residuária, respectivamente, constataram um aumento significativo nos teores de sódio dos solos.
Analisando-se os resultados dos coeficientes de variação, verifica-se uma baixa variação do teor de sódio trocável para o SAS, e uma média variação para o SN e os demais solos analisados. Como mostra a Figura 2 (d), constata-se que a condutividade elétrica das águas de irrigação proporcionou um efeito crescente nos teores de sódio dos solos.

Tabela 4: Média das alturas de planta $\left(A P_{L}\right)$, do diâmetro do caule (DC) e do número de folhas (NF) para os diferentes tratamentos

\begin{tabular}{cccccc} 
& $\begin{array}{c}\text { Época de } \\
\text { Avaliação } \\
\text { /DAS }\end{array}$ & AP & EE & EF & AS \\
\hline APL/cm & 40 & $17,30 \mathrm{a}$ & $15,30 \mathrm{a}$ & $14,32 \mathrm{a}$ & $15,22^{\underline{a}}$ \\
& 60 & $32,75 \mathrm{a}$ & $34,13 \mathrm{a}$ & $36,67 \mathrm{a}$ & $35,95^{\underline{a}}$ \\
& 80 & $41,34 \mathrm{a}$ & $45,45 \mathrm{a}$ & $53,63 \mathrm{a}$ & $46,40^{\underline{a}}$ \\
\hline $\mathrm{DC} / \mathrm{mm}$ & 40 & $6,18 \mathrm{a}$ & $6,64 \mathrm{a}$ & $6,45 \mathrm{a}$ & $6,20^{\underline{a}}$ \\
& 60 & $7,41 \mathrm{~b}$ & $8,91 \mathrm{ab}$ & $9,83 \mathrm{a}$ & $8,43 \mathrm{ab}$ \\
& 80 & $8,17 \mathrm{~b}$ & $10,95 \mathrm{a}$ & $10,65 \mathrm{a}$ & $9,32 \mathrm{ab}$ \\
\hline NF/unid. & 40 & $10,00 \mathrm{a}$ & $9,33 \mathrm{a}$ & $9,33 \mathrm{a}$ & $10,00 \mathrm{a}$ \\
& 60 & $16,33 \mathrm{a}$ & $17,17 \mathrm{a}$ & $19,17 \mathrm{a}$ & $17,50^{\mathrm{a}}$ \\
& 80 & $16,33 \mathrm{a}$ & $17,33 \mathrm{a}$ & $18,17 \mathrm{a}$ & $16,00 \mathrm{a}$
\end{tabular}

$\overline{\mathrm{AP}}$ - Água de Poço (0,97 dS m $\left.{ }^{-1}\right)$; EE - Esgoto da Estação de Tratamento (1,03 dS m $\left.{ }^{-1}\right)$;

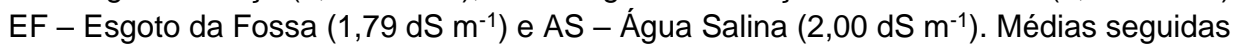
de letras minúsculas na mesma linha não diferem estatisticamente pelo teste de Tukey a 5\%. Fonte: Próprio Autor (2018).

Tratando-se dos aspectos biométricos da cultura do girassol, observa-se pela Tabela 4 que o aumento da salinidade das águas de irrigação não afetou os parâmetros Altura de Planta $(A P L)$, Diâmetro do Caule (DC) e Número de Folhas (NF), constatando-se que os diferentes tratamentos aplicados proporcionaram condições semelhantes às plantas dos diferentes tratamentos nos períodos de avaliação.

A análise de variância aplicada às médias do diâmetro do caule revelou que, aos 60 DAS, a média do DC das plantas irrigadas com 0 tratamento EF apresentou significância apenas com relação à média do $\mathrm{DC}$ do tratamento $\mathrm{AP}$. Aos 80 DAS, os tratamentos com as águas residuárias apresentaram médias superiores do parâmetro DC com relação aos outros tratamentos. Aos 40 DAS, não houve diferença significativa entre os tratamentos.

Para a análise estatística das médias do parâmetro número de folhas (NF), os diferentes tratamentos aplicados não ocasionaram alterações no desenvolvimento das folhas, ou seja, sem diferença estatística significativa para as diferentes épocas de avaliação. Da mesma forma, Morais et al. (2011) aplicaram águas com diferentes salinidades e observaram que 0 parâmetro NF não foi influenciado, apresentando evolução semelhantes ao longo de todo o ciclo para os diferentes tratamentos e para as diferentes épocas de avaliação. Já Gomes et al. (2015) e Oliveira et al. (2010) aplicaram águas com diferentes salinidades e observaram um declínio linear no número de folhas com o aumento da condutividade elétrica da água.

Portanto, pode-se inferir, pela Figura 3, que a salinidade das águas de irrigação aplicada sobre a cultura do girassol não apresentou correlação com tais parâmetros, visto que não ficou evidente uma tendência de crescimento ou decrescimento relacionado ao aumento ou diminuição da condutividade elétrica das águas de irrigação. Comportamento contrário foi observado por Centeno (2013) e Travassos (2014) que, ao estudarem o efeito da salinidade sobre a cultura do girassol, constataram efeito negativo sobre o parâmetro altura de planta com o aumento da condutividade elétricas das águas de irrigação. 
Observou-se um maior crescimento do diâmetro do caule em função da salinidade nos tratamentos em que a irrigação foi realizada por efluente oriundo da fossa e da estação de tratamento. Tal característica pode estar relacionada à maior concentração de nitrogênio nesses tratamentos, fato também evidenciado por Vrânceanu (1977).
Oliveira (2015) não encontrou efeito significativo dos tratamentos aplicados sobre o parâmetro DC, enquanto que Maciel et al. (2012) e Santos Júnior et al. (2016) observaram que o diâmetro do caule da cultura do girassol reduziu com o aumento da salinidade da água de irrigação.

Figura 3: Valores médios da altura de planta (a), diâmetro do caule (b) e número de folhas

(c) com relação à condutividade elétrica das águas de cada tratamento para as diferentes épocas de avaliação, com seus respectivos coeficientes de determinação

$$
\text { -40 DAS } 60 \mathrm{DAS} \triangle 80 \mathrm{DAS}
$$

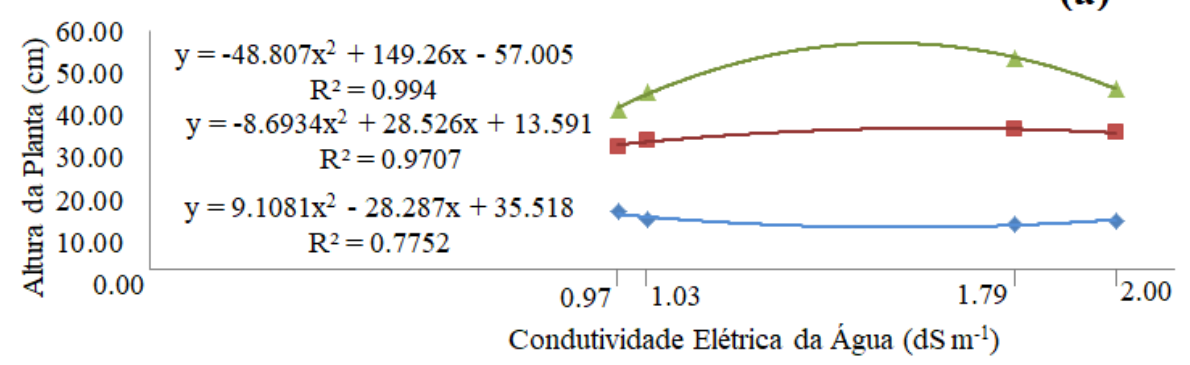

(b)

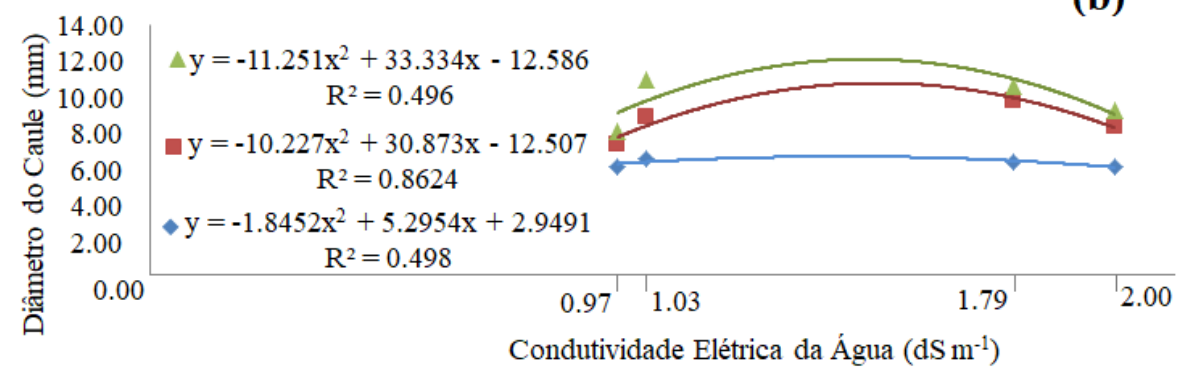

(c)

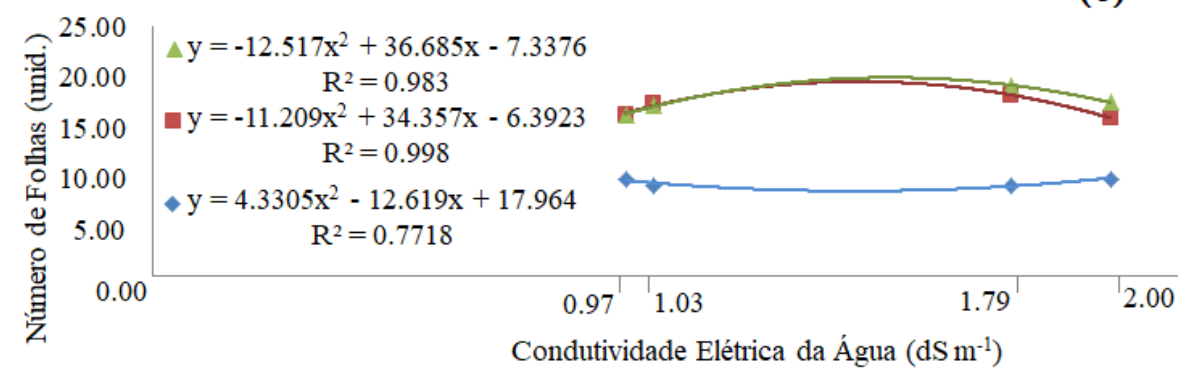

Água de Poço $\left(0,97 \mathrm{dS} \mathrm{m} \mathrm{m}^{-1}\right)$; Esgoto da Estação de Tratamento $\left(1,03 \mathrm{dS} \mathrm{m}^{-1}\right)$; Esgoto da Fossa $\left(1,79 \mathrm{dS} \mathrm{m}^{-1}\right)$ e Água Salina $\left(2,00 \mathrm{dS} \mathrm{m}^{-1}\right)$. Fonte: Próprio Autor (2018).

Tabela 5: Médias dos diâmetros internos (DIC) e externos (DEC) dos capítulos para os diferentes tratamentos, em $\mathrm{cm}$.

\begin{tabular}{rcccc}
\cline { 2 - 5 } & AP & EE & EF & AS \\
\hline DIC & $4,38 \mathrm{~b}$ & $5,53 \mathrm{a}$ & $4,68 \mathrm{ab}$ & $4,70 \mathrm{ab}$ \\
DEC & $12,07 \mathrm{a}$ & $12,95 \mathrm{a}$ & $12,15 \mathrm{a}$ & $12,65 \mathrm{a}$ \\
\hline
\end{tabular}

AP - Água de Poço (0,97 dS m $\left.{ }^{-1}\right)$; EE - Esgoto da Estação de Tratamento (1,03 dS m -1 $^{-1}$; EF - Esgoto da Fossa $\left(1,79 \mathrm{dS} \mathrm{m}^{-1}\right)$ e AS - Água Salina $\left(2,00 \mathrm{dS} \mathrm{m}^{-1}\right)$. Médias seguidas de letras minúsculas na mesma linha não diferem estatisticamente pelo teste de Tukey a $5 \%$. Fonte: Próprio Autor (2018). 
De acordo com a Tabela 5, a análise de variância não apresentou diferença significativa para nenhum dos tratamentos para o parâmetro diâmetro externo do capítulo (DEC), podendo-se afirmar que a salinidade das diferentes fontes de irrigação não afetou tal parâmetro. Com relação ao diâmetro interno do capítulo (DIC), o Teste de Tukey mostrou significância apenas para 0 tratamento com o Esgoto da Estação de Tratamento com relação à água de poço, com médias iguais a 5,53 e 4,38 cm, respectivamente.

Pode-se inferir que os diferentes tratamentos aplicados não influenciaram nenhum dos dois parâmetros analisados, obtendo-se o coeficiente de determinação de 0,1136 e 0,0555 para os dados de DIC e DEC, respectivamente. Santos et al. (2017) e Guedes Filho et al. (2015) verificaram que tanto o diâmetro interno quanto o externo foram reduzidos linearmente com o aumento da salinidade das águas de irrigação. Travassos et al. (2011) notaram que o maior diâmetro interno do capítulo do girassol foi obtido com a água com menor salinidade, e o menor diâmetro, com a água de maior salinidade.

A Figura 4 apresenta as curvas de regressão para os parâmetros DIC e DEC, sendo o modelo polinomial o que melhor se ajustou aos resultados.

Com relação ao parâmetro fitomassa (Tabela 6), na análise de variância aplicada às médias das fitomassas secas e frescas, constatou-se que os parâmetros fitomassa fresca da raiz (FFR), fitomassa seca da parte aérea (FSPA) e fitomassa seca da raiz (FSR) não apresentaram diferença significativa para os diferentes tratamentos aplicados. Porém, no parâmetro fitomassa fresca da parte aérea (FFPA), os tratamentos com as águas residuárias apresentaram médias superiores ao tratamento com água de poço.

Figura 4: Valores médios do diâmetro interno (a) e do diâmetro externo (b) do capítulo com relação à condutividade elétrica das águas de cada tratamento, com seus respectivos coeficientes de determinação

(a)

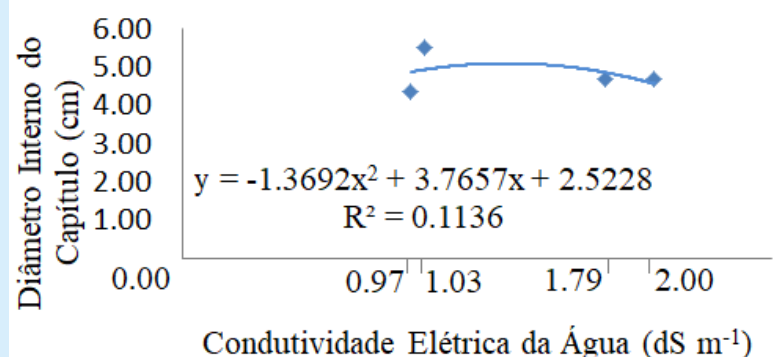

(b)

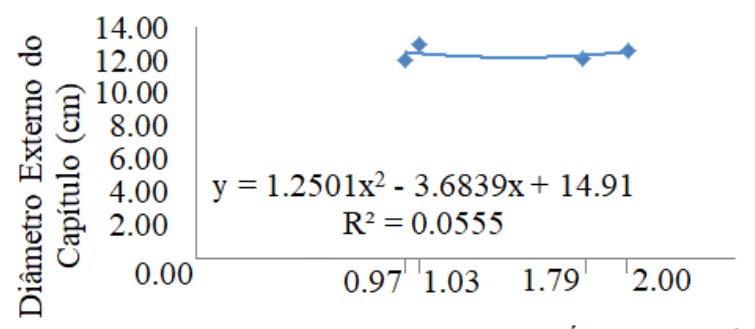

Condutividade Elétrica da Água $\left(\mathrm{dS} \mathrm{m}^{-1}\right)$

Água de Poço $\left(0,97 \mathrm{dS} \mathrm{m}^{-1}\right)$; Esgoto da Estação de Tratamento $\left(1,03 \mathrm{dS} \mathrm{m}^{-1}\right)$; Esgoto da Fossa $\left(1,79 \mathrm{dS} \mathrm{m}^{-1}\right)$ e Água Salina $\left(2,00 \mathrm{dS} \mathrm{m}^{-1}\right)$. Fonte: Próprio Autor (2018).

Tabela 6: Médias das fitomassas fresca da parte aérea (FFPA), fresca do capítulo (FFC), fresca da raiz (FFR), fresca total (FFT) e das fitomassas seca da parte aérea (FSPA), seca do capítulo (FSC), seca da raiz (FSR) e seca total (FST), para os diferentes tratamentos, em gramas

\begin{tabular}{ccccc} 
& AP & EE & EF & AS \\
\hline FFPA & $37,87 \mathrm{~b}$ & $57,88 \mathrm{a}$ & $59,38 \mathrm{a}$ & $51,58 \mathrm{ab}$ \\
FFC & $50,82 \mathrm{c}$ & $81,35 \mathrm{a}$ & $66,42 \mathrm{abc}$ & $54,22 \mathrm{bc}$ \\
FFR & $27,20 \mathrm{a}$ & $27,63 \mathrm{a}$ & $31,92 \mathrm{a}$ & $33,53 \mathrm{a}$ \\
FSPA & $7,14 \mathrm{a}$ & $9,76 \mathrm{a}$ & $10,69 \mathrm{a}$ & $9,68 \mathrm{a}$ \\
FSC & $7,30 \mathrm{~b}$ & $11,06 \mathrm{a}$ & $9,74 \mathrm{ab}$ & $8,29 \mathrm{ab}$ \\
FSR & $3,48 \mathrm{a}$ & $3,99 \mathrm{a}$ & $6,11 \mathrm{a}$ & $6,14 \mathrm{a}$ \\
\hline FFT & $115,88 \mathrm{~b}$ & $166,87 \mathrm{a}$ & $157,72 \mathrm{a}$ & $139,33 \mathrm{ab}$ \\
FST & $17,92 \mathrm{~b}$ & $24,81 \mathrm{ab}$ & $26,54 \mathrm{a}$ & $23,70 \mathrm{ab}$
\end{tabular}

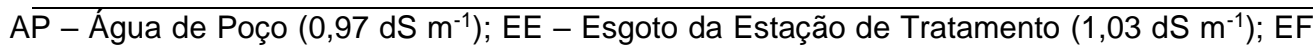
- Esgoto da Fossa $\left(1,79 \mathrm{dS} \mathrm{m}^{-1}\right)$ e AS - Água Salina $\left(2,00 \mathrm{dS} \mathrm{m}^{-1}\right)$. Médias seguidas de letras minúsculas na mesma linha não diferem estatisticamente pelo teste de Tukey a $5 \%$.

Fonte: Próprio Autor (2018). 
Já no capítulo, o parâmetro fitomassa fresca (FFC) não apresentou diferença significativa entre os tratamentos com águas residuárias, porém, o esgoto da estação apresentou média significativa com relação aos tratamentos AP e AS, assim como na massa seca do capítulo (FSC), onde se mostrou significativo apenas com relação ao AP.

Para o parâmetro fitomassa fresca total (FFT), as maiores médias obtidas foram dos tratamentos EF e EE, correspondendo a 157,72 e $166,87 \mathrm{~g}$, respectivamente, as quais, por sua vez, foram superiores ao tratamento com água de poço. Já no parâmetro fitomassa seca total (FST), o tratamento EF apresentou a maior média, correspondendo a $26,54 \mathrm{~g}$, que foi significativa apenas com 0 tratamento AP, que apresentou média igual a 17,92g.

Observou-se na presente pesquisa que, exceto nos parâmetros FFR e FSR, as maiores médias obtidas para os demais parâmetros relacionados às fitomassas frescas e secas foram das plantas irrigadas com os tratamentos com águas residuárias. De acordo com Lucas Filho et al. (2002), o maior teor de nutrientes no solo devido à irrigação com águas residuárias pode levar a um melhor desenvolvimento da planta, obtendo uma maior produção de matéria fresca e seca. E desde que a concentração dos diferentes nutrientes no solo esteja equilibrada de acordo com as necessidades da cultura, a maior produção de matéria seca poderá implicar em uma maior produtividade.

Conforme as Figuras 5 e 6, observa-se que, exceto no parâmetro FFR e FSR, a salinidade das águas de irrigação não afetou os parâmetros de fitomassas secas e frescas nem os valores totais das fitomassas, visto que não houve um comportamento com tendência de crescimento ou decrescimento ao associar a condutividade elétrica das águas de irrigação com os parâmetros de fitomassas. Já nos parâmetros FFR e FSR, apesar dos valores não apresentarem diferença significativa, $\mathrm{O}$ aumento da salinidade das águas de irrigação proporcionou um aumento na massa fresca e seca da raiz, sendo os menores valores observados correspondentes à menor salinidade, e o maior valor correspondente à água com maior salinidade.

Távora et al. (2001) afirmam que o elevado teor de sais na região onde o solo e as raízes entram em contato reduz a capacidade de absorção de água pelas raízes, causando estresse hídrico. Tal estresse, segundo Gomes
(2005) e Ungaro et al. (2009), tende a produzir raízes maiores com maior massa e se aprofundar mais no solo que uma planta sem estresse hídrico.

Divergindo dos resultados da presente pesquisa, Centeno et al. (2014) observaram uma redução linear na fitomassa fresca do capítulo e nas fitomassas secas da parte aérea e da raiz do girassol com o aumento da salinidade das águas de irrigação. Da mesma forma, Travassos et al. (2012) constataram uma redução linear com o aumento da salinidade dos parâmetros fitomassa fresca e seca da parte aérea. Já Barros (2013) notou que as fitomassas frescas e secas da parte aérea das plantas irrigadas com água residuária tratada obtiveram médias superiores aos das plantas irrigadas com água de abastecimento, apesar de a primeira possuir uma condutividade elétrica maior que a última.

Contrários aos resultados obtidos no presente trabalho, diversos estudos (OLIVEIRA et al., 2010; MACIEL et al., 2012; GUEDES FILHO et al., 2015; GOMES et al., 2015; AZEVEDO et al., 2016) apresentam um decréscimo na massa fresca e seca da cultura do girassol com o aumento da salinidade das águas de irrigação, devido aos sais presentes nas águas diminuírem o potencial osmótico do solo em que estão cultivados, atuando de forma negativa sobre o processo fisiológico do vegetal, reduzindo a absorção de água pelas raízes, inibindo a atividade meristemática e o alongamento celular, bem como dificultando seu crescimento e desenvolvimento (AYERS; WESTCOT, 1999).

O presente trabalho apresenta a possibilidade de utilização de águas residuárias e salinas, com condutividade elétrica de até 2,0 dS $\mathrm{m}^{-1}$, no cultivo do Girassol Anão de Jardim, visto que as análises biométricas da cultura se desenvolveram em condições semelhantes e sem diferença significativa para a maioria dos parâmetros biométricos analisados, comprovando que, em ambientes de escassez hídrica, como as regiões áridas e semiáridas, a exemplo do Nordeste brasileiro, onde já é comum encontrar águas de má qualidade e com alto teor de sais, o uso dessas águas de irrigação é possível sem afetar o desenvolvimento do girassol. Porém, no solo utilizado no estudo, observou-se aumento significativo em todos os parâmetros avaliados referentes à salinidade após a aplicação dos tratamentos, mostrando que, a curto prazo, sem uma lixiviação adequada dos sais, os mesmos se acumularão e poderão no futuro afetar o 
desenvolvimento da cultura.

\section{CONCLUSÕES}

Acréscimos na salinidade das águas de irrigação proporcionaram um aumento na condutividade elétrica do extrato de saturação do solo, no percentual e no teor de sódio trocável do solo.
Os parâmetros AP, DC e NF não foram afetados pelo acréscimo da salinidade da água de irrigação nos períodos de avaliação.

O aumento da condutividade elétrica das águas de irrigação proporcionou um maior crescimento das fitomassas das raízes.

Salinidades entre 0,97 a 2,00 dS m-1 não afetaram de forma negativa os parâmetros biométricos da cultura do Girassol.

Figura 5: Médias das fitomassas fresca da parte aérea (a), seca da parte aérea (b), fresca do capítulo (c), seca do capítulo (d), fresca da raiz (e) e seca da raiz (f) com relação à CEa de cada tratamento, com seus respectivos coeficientes de determinação
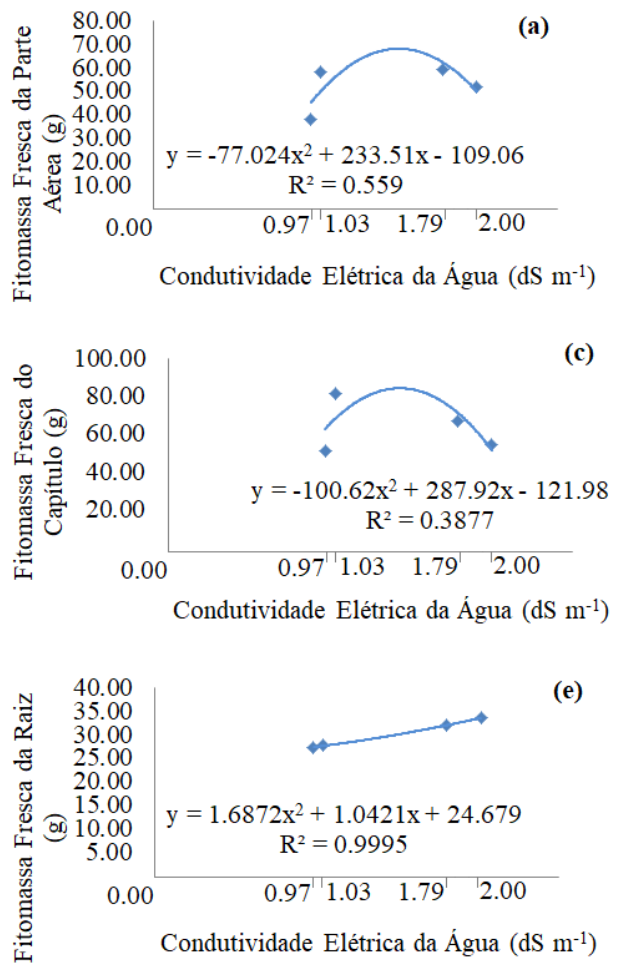

(c)
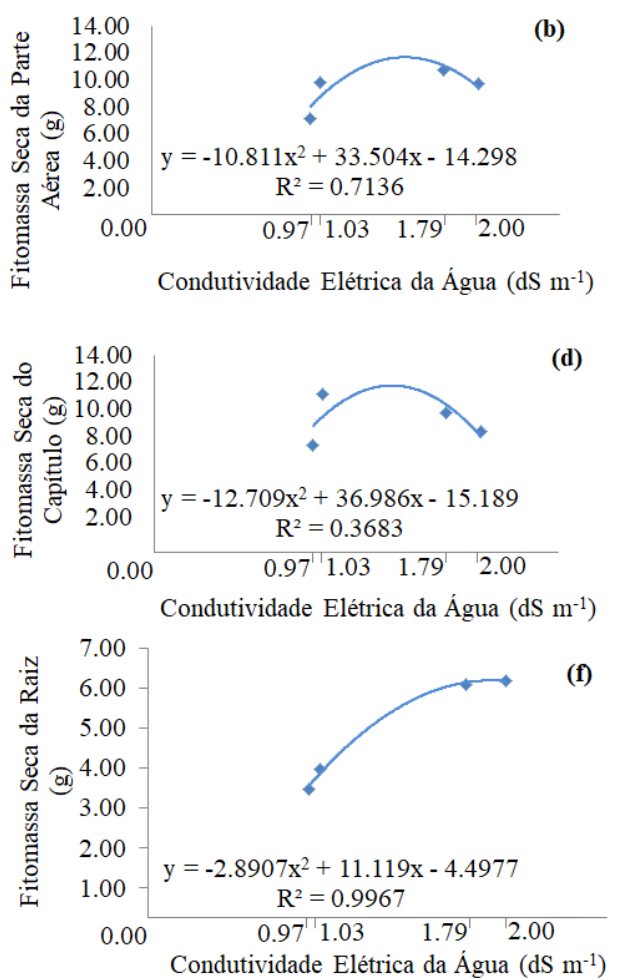

Água de Poço (0,97 dS m $\left.{ }^{-1}\right)$; Esgoto da Estação de Tratamento (1,03 dS m $\left.{ }^{-1}\right)$; Esgoto da Fossa $\left(1,79 \mathrm{dS} \mathrm{m}^{-1}\right)$ e Água Salina $\left(2,00 \mathrm{dS} \mathrm{m}^{-1}\right)$. Fonte: Próprio Autor (2018).

Figura 6: Valores médios da fitomassa fresca total (a) e seca total (b) com relação à CEa de cada tratamento, com seus respectivos coeficientes de determinação

(a)

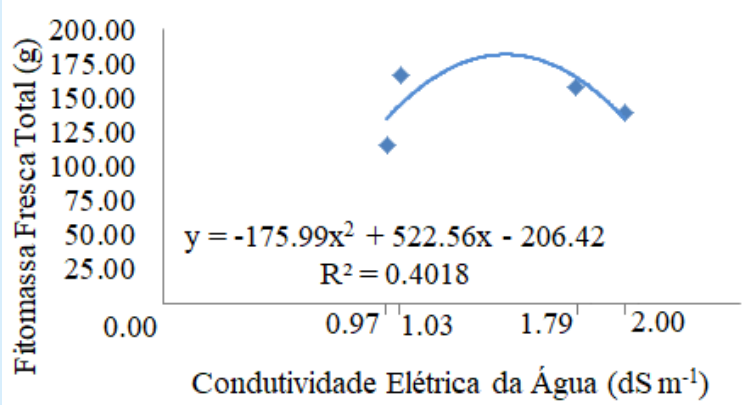

(b)

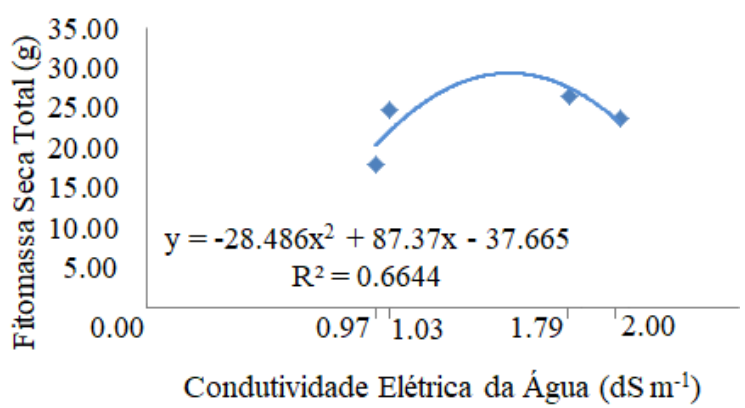

Água de Poço (0,97 dS m $\left.{ }^{-1}\right)$; Esgoto da Estação de Tratamento (1,03 dS m $\left.\mathrm{m}^{-1}\right)$; Esgoto da Fossa $\left(1,79 \mathrm{dS} \mathrm{m}^{-1}\right)$ e Água Salina (2,00 dS m-1). Fonte: Próprio Autor (2018). 


\section{AGRADECIMENTOS}

A Coordenação de Aperfeiçoamento de Pessoal de Nível Superior (CAPES) pelo suporte financeiro.

\section{REFERÊNCIAS}

ALLEN, R. G.; PEREIRA, L. S.; RAES, D.; SMITH, M. Crop evapotranspiration. FAO Irrigation and Drainage Paper No 56. 300 p. 1998.

ANDRADE FILHO, J.; SOUSA NETO, O. N.; DIAS, N. da S.; NASCIMENTO, I. B. do; MEDEIROS, J. F.; COSME, C. R. Atributos químicos de solo fertirrigado com água residuária no semiárido brasileiro. Revista Irriga, v.18, n.4, p. 661-674, out./dez. 2013.

APHA. Standard Methods for the examination of water and wastewater. American Public Health Association, American Water Works Association, Water Environmental Federation, 20. ed. Washington. 2005.

AYERS, R. S.; WESTCOT, D. W. A qualidade da água na agricultura. 2. ed. Campina Grande: UFPB, 1999, 218p. (Estudos FAO. Irrigação e Drenagem, 29).

AZEVEDO, B. M.; VASCONCELOS, D. V.; BOMFIM, G. V.; VIANA, T. V. A.; NASCIMENTO NETO, J. R.; OLIVEIRA, K. M. A. S. Production and yield response factor of sunflower under different irrigation depths. Revista Brasileira de Engenharia Agrícola e Ambiental, v. 20, n. 5, p. 427-433, 2016.

BALKS, M. R.; BOND, W. J.; SMITH, C. J. Effects of sodium accumulation on soil physical properties under an effluent-irrigated plantation. Autralian Journal of Soil Research, v.36, p. 821-830, 1998.

BARROS, H. M. M. Cultivo do girassol irrigado com efluente doméstico tratado e adubações orgânica e inorgânica. 2013. 151f. Tese (Doutorado em Engenharia Agrícola - Irrigação e Drenagem) - Centro de Tecnologia e Recursos Naturais, Universidade Federal de Campina Grande, Campina Grande, 2013.

BATISTA, M. J.; NOVAES, F.; SANTOS, D. G.; SUGUINO, H. H. Drenagem como instrumento de dessalinização e prevenção da salinização de solos. 2. ed., rev. e ampliada. Brasília: CODEVASF, 2002. 216p.

BISCARO, G. A.; MACHADO, J. R.; TOSTA, M. da. S.; MENDONÇA, V.; SORATTO, R. P.; CARVALHO, L. A. Adubação nitrogenada em cobertura no girassol irrigado nas condições de Cassilândia-MS. Ciência e Agrotecnologia, v. 32, n. 05, p. 1366-1373, 2008.

BORGHETTI, J. R.; SILVA, W. L. C.; NOCKO, H. R.; LOYOLA, L. N.; CHIANCA, G. K.; BOJANIC, A.;
OSTRENSKY NETO, A.; TAVARES, M. H.; BOSCARDIN, N. R. Agricultura irrigada sustentável no Brasil: Identificação de áreas prioritárias. 1. ed. Brasília: FAO - Organização das Nações Unidas para a Alimentação e a Agricultura, 2017. 243p.

BOUWER, $\mathrm{H}$. Integrated water management: emerging issues and challenges. Agricultural Water Mangement, v.45, p.217-228, 2000.

CAVALCANTE, L. F.; VIEIRA, M. S.; SANTOS, A. F.; OLIVEIRA, W. M.; NASCIMENTO, J. A. M. Água salina e esterco bovino líquido na formação de mudas de goiabeira cultivar paluma. Revista Brasileira de Fruticultura (Impresso), v. 32, p. 251-261, 2010.

CAVALCANTE JUNIOR, E. G.; MEDEIROS, J. F. de; MELO, T. K. de; ESPINOLA SOBRINHO, J.; BRISTOT, G.; ALMEIDA, B. M. de. Necessidade hídrica da cultura do girassol irrigado na chapada do Apodi. Revista Brasileira de Engenharia Agrícola e Ambiental (Online), v. 17, n.3, p. 261-267, 2013.

CENTENO, C. R. M. Crescimento e componentes de produção do girassol irrigado com água salinizada e adubação nitrogenada. 2013. 127f. Tese (Doutorado em Engenharia Agrícola - Irrigação e Drenagem) - Programa de Engenharia Agrícola, Universidade Federal de Campina Grande, Campina Grande, 2013.

; SANTOS, J. B. dos; XAVIER, D. A.; AZEVEDO, C. A. V. de; GHEYI, H. R. Componentes de produção do girassol Embrapa 122-V2000 sob salinidade da água e adubação nitrogenada. Revista Brasileira de Engenharia Agrícola e Ambiental (Online), v. 18, p.39-45, 2014.

COSTA, M. E. da; MORAIS, F. A.; SOUZA, W. C. M.; GURGEL, M. T.; OLIVEIRA, F. H. T. Estratégias de irrigação com água salina na mamoneira. Revista Ciência Agronômica (UFC. Online), v. 44, n.1, p. 3443, jan./mar. 2013.

FEIGIN, A.; RAVINA, I.; SHALHEVET, J. Irrigation with treated sewage effluent: management for environmental protection. Berlin: Springer-Verlag, 1991. $224 p$.

GOMES, E. M. Parâmetros básicos para a irrigação sistemática do girassol (Helianthus annuus L.). 2005. 117 f. Tese (Doutorado em Recursos Hídricos) Faculdade de Engenharia Civil, Arquitetura e Urbanismo, Universidade Estadual de Campinas, 2005.

GOMES, K. R.; SOUSA, G. G. de; LIMA, F. A.; VIANA, T. V. A.; AZEVEDO, B. M. de; SILVA, G. L. Irrigação com água salina na cultura do girassol (Helianthus annuus L.) em solo com biofertilizante bovino. Irriga, v. 20, n. 4, p. 680-693, out./dez. 2015. 
GOMES, V. S. Influência da aplicação da água residuária nas características químicas de um Planossolo Nátrico na região semiárida. 2016. 48p. Dissertação (Mestrado em Ciência do Solo) Programa de Pós-Graduação em Ciência do Solo, Universidade Federal da Paraíba, Areal. 2016.

GUEDES FILHO, D. H.; SANTOS, J. B.; GHEYI, H. R.; CAVALCANTE, L. F.; SANTOS JUNIOR, J. A. Componentes de produção e rendimento do girassol sob irrigação com águas salinas e adubação nitrogenada. Irriga, v. 20, n. 3, p. 514-527, jul./set. 2015.

HOLANDA, J. S.; AMORIM, J. R. A.; FERREIRA NETO, M.; HOLANDA, A. C.; SÁ, F. V. S. Qualidade da água para irrigação. In: GHEYI, H. R.; DIAS, N. da S.; LACERDA, C. F. de.; GOMES FILHO, E. (Ed.). Manejo da salinidade na agricultura: estudos básicos e aplicados. 2. ed. Fortaleza: Instituto Nacional de Ciência e Tecnologia em Salinidade (INCTSal), 2016.

HOLANDA FILHO, R. S. F. de; SANTOS, D. B. dos; AZEVEDO, C. A. V. de; COELHO, E. F.; LIMA, V. L. A. de. Água salina nos atributos químicos do solo e no estado nutricional da mandioqueira. Revista Brasileira de Engenharia Agrícola e Ambiental, v. 15, n.1, p. 60-66, 2011.

JARDINI, D. C.; SCARAMUZZA, W. L. M. P.; WEBER, O. L. S.; BORBA FILHO, A. B.; FERNANDES, D. A. Absorção de nutrientes em genótipos de girassol. Pesquisa Agropecuária Tropical, v. 44, n. 4, p. 434442, 2014.

JENSEN, P. K.; MATSUNO, Y.; VAN DER HOEK, W.; CAIRNCROSS, S. Limitations of irrigation water quality guidelines from a multiple use perspective. Irrigation and Drainage Systems, v.15, p.117-128, 2001.

LEAL, R. M. P. Efeito da irrigação com efluente de esgoto tratado em propriedades químicas de um latossolo cultivado com cana-de-áçucar. 2007. 109f. Dissertação (Mestrado em Agronomia) - Escola Superior de Agricultura "Luiz de Queiroz", Universidade de São Paulo, São Paulo, 2007.

LIMA NETO, A. J.; CAVALCANTE, L. F.; NUNES, J. C.; SOUTO, A. G. L.; BEZERRA, F. T. C. Mudas de tamarindeiro irrigadas com água salina em solo sem e com biofertilizantes. Irriga, v. 20, n.4, p. 730-744, out./dez. 2015.

LOBO, T. F.; GRASSI FILHO, H. Níveis de lodo de esgoto na produtividade do girassol. Revista Ciencia del Suelo e Nutrición Vegetal, Temuco, Chile, v.7, n.3, p.16-25, 2007.

LUCAS FILHO, M.; PEREIRA, M. G.; SILVA, D. A.;
NETO, C. O. A.; MELO, H. N. S.; SILVA, G. B. Águas residuárias - Alternativa de reúso na cultura de girassol (Helianthus annuus L.). In: SIMPÓSIO ÍTALO BRASILEIRO DE ENGENHARIA SANITÁRIA E AMBIENTAL, 6., 2002, Vitória. Anais... Rio de JaneiroRJ: ABES, 2002.

MAAS, E. V. Salt tolerance of plants. Applied Agriculture Research, v.1, p.12-26, 1986.

MASSOUD, F. I. A note on the need for accented definitions and method of characterization of salts affected soils. In: REUNION DA LA SUBCOMICION DE SUELOS SALINOS. Sevilla: Iryda, 1971.

MACIEL, M. P.; SOARES, T. M.; GHEYI, H. R.; REZENDE, E. P. L ; OLIVEIRA, G. X. S. Produção de girassol ornamental com uso de águas salobras em sistema hidropônico NFT. Revista Brasileira de Engenharia Agrícola e Ambiental (Online), v. 16, n. 2, p. 165-172, 2012.

MEDEIROS, R. F.; CAVALCANTE, L. F.; MESQUITA, F. O.; RODRIGUES, R. M.; SOUSA, G. G.; DINIZ, A. A. Crescimento inicial do tomateiro-cereja sob irrigação com águas salinas em solo com biofertilizantes bovino. Revista Brasileira de Engenharia Agrícola e Ambiental (Online), v. 15, n. 5, p. 505-511, 2011.

MEDEIROS, J. F.; GHEYI, H. R.; COSTA, A. R. F. C.; TOMAZ, H. V. Q. Manejo do solo-água-planta em áreas afetadas por sais. In: GHEYI, H. R.; DIAS, N. da S.; LACERDA, C. F. de.; GOMES FILHO, E. (Ed.). Manejo da salinidade na agricultura: estudos básicos e aplicados. 2. ed. Fortaleza: Instituto Nacional de Ciência e Tecnologia em Salinidade (INCTSal), 2016.

MOLOZZI, J.; SILVA, A.; PINHEIRO, A.; HEPP, L. U. A cultura do arroz influenciando a distribuição de macrófitas aquáticas. Perspectiva, v. 29, p.61-68, 2005.

MORAIS, F. A.; GURGEL, M. T.; OLIVEIRA, F. H. T.; MOTA, A. F. Influência da irrigação com água salina na cultura do girassol. Revista Ciência Agronômica, v. 42, n. 2, p. 327-336, abr./jun. 2011.

MOURÃO, A. C. Variabilidade espacial da salinidade em solo cultivado com videira irrigada no vale do São Francisco em Petrolina-PE. 2014. $52 f$. Dissertação (Mestrado em Irrigação e Drenagem) Universidade Federal Rural do Semi-Árido, Mossoró, 2014.

NASCIMENTO, J. S.; FIDELES FILHO, J. Crescimento, produção e alterações químicas do solo em algodão irrigado com água de esgotos sanitários tratados. Revista Caatinga, v. 28, n. 2, p. 36-45, abr./jun. 2015. OLIVEIRA, F. A.; OLIVEIRA, F. R. A.; CAMPOS, M. S.; OLIVEIRA, M. K. T.; MEDEIROS, J. F.; SILVA, O. 
M. P. Interação entre salinidade e fontes de nitrogênio no desenvolvimento inicial da cultura do girassol. Revista Brasileira de Ciências Agrárias (Online), Recife, v. 5, n. 4, p. 479-484, out./dez. 2010.

OLIVEIRA, P. C. P.; GLOAGUEN, T. V.; SANTOS, D. L.; GONÇALVES, R.A.B. Produção de moranga irrigada com esgoto doméstico tratado. Revista Brasileira de Engenharia Agrícola e Ambiental (Online), v. 17, n.8, p. 861-867, 2013.

OLIVEIRA, M. L. A. Uso de água residuária para produção de girassol ornamental. 2015. $65 f$. Dissertação (Mestrado em Engenharia Agrícola) Centro de Ciências Agrárias, Ambientais e Biológicas, Universidade Federal do Recôncavo da Bahia, Cruz das Almas, 2015.

PALÁCIO, H. A. de Q.; NETO, J. A. C.; TEIXEIRA, A. dos S.; ANDRADE, E. M. de. Caracterização da potencialidade de uso das águas subterrâneas no vale do Trussu-CE. Revista Ciência Agronômica, v. 35, n. 2, p.316-324, jul./dez. 2004.

PEDRERO, F.; KALAVROUZIOTIS, I.; ALARCÓN, J. J.; KOUKOULAKIS, P.; ASANO, T. Use of treated municipal wastewater in irrigated agriculture - Review of some practices in Spain and Greece. Agricultural Water Management, v. 97, p.1233-1241, 2010.

PORTO FILHO, F. Q.; MEDEIROS, J. F.; GHEYI, H. R.; DIAS, N. S.; SOUSA, P. S.; DANTAS, D.C. Evolução da salinidade e do $\mathrm{pH}$ de um solo sob cultivo de melão irrigado com água salina. Revista Brasileira de Engenharia Agrícola e Ambiental (Impresso), v. 15 , p. 1130-1137, 2011.

RESENDE, R. S.; AMORIM, J. R. A.; CRUZ, M. A. S.; MENESES, T. N. Distribuição espacial e lixivição natural de sais em solos do Perímetro Irrigado Califórnia, em Sergipe. Revista Brasileira de Engenharia Agrícola e Ambiental (Online), v. 18, p. S46-S52, 2014

RICHARDS, L. A. (Ed). Diagnosis and improvement of saline and alkali soils. Washington, DC: United States Salinity Laboratory Staff, USDA, 160p. 1954. (Agriculture Handbook, 60).

SANTOS JÚNIOR, J. A.; GHEYI, H. R.; CAVALCANTE, A. R.; FRANCILINO, A. H.; PEREZ-MARIN, A. M. Crescimento de girassóis ornamentais sob estresse salino em hidroponia de baixo custo. Irriga (UNESP), Botucatu, v. 21, n. 3, p. 591-604, 2016.

SANTOS, J. B. dos; CENTENO, C. R. M.; AZEVEDO, C. A. V. de; GHEYI, H. R.; LIMA, G. S.; LIRA, V. M. Crecimiento del girasol (Helianthus annuus L.) en función de la salinidad del agua de riego con fertilización nitrogenada. Revista Agrociencia, v. 51, p. 649-660, 2017.
SILVA, F. C. da (Ed.). Manual de análises químicas de solos, plantas e fertilizantes. 2. ed. Brasília, DF: Embrapa Informação Tecnológica; Rio de Janeiro: Embrapa Solos, 2009. 627 p. il.

TAIZ, L.; ZEIGER, E. Fisiologia vegetal. 5. ed. Porto Alegre: Artmed, 2013. 918 p.

TAN, K. H. Principles of soil chemistry. New York: Marcel Dekker, 1982. 267p.

TÁVORA, F. J. A. F.; FERREIRA, R. G.; HERNANDEZ, F. F. F. Crescimento e relações hídricas em plantas de goiabeira submetidas a estresse salino com $\mathrm{NaCl}$. Revista Brasileira de Fruticultura, Jaboticabal, v. 23, n. 2, p. 441-446. 2001.

TELLES, D. A. Aspectos da utilização de corpos d'água que recebem o esgoto sanitário na irrigação de culturas agrícolas. In: NUVOLARI, A. (Org.). Esgoto Sanitário: coleta, transporte, tratamento e reúso agrícola. 2. ed. Rev. Ampl. São Paulo: Edgard Blucher, 2011, v. único, p. 507-528.

TRAVASSOS, K. D.; SOARES, F. A. L.; GHEYI, H. R.; SILVA, D. R. S.; NASCIMENTO, A. K. S.; DIAS, N. S. Produção de aquênio do girassol irrigado com água salobra. Revista Brasileira de Engenharia Agrícola e Ambiental (Online), v. 15, n. 4, p. 371-376, 2011.

; GHEYI, H. R.; SOARES, F. A. L.; BARROS, H. M. M.; DIAS, N. S.; UYEDA, C. A.; SILVA, F. V. Crescimento e desenvolvimento de variedades de girassol irrigado com água salina. Irriga, v.1, p.324339, 2012.

Biometria e produção de cultivares de girassol irrigado com águas de diferentes salinidades. 2014. 164f. Tese (Doutorado em Engenharia Agrícola - Irrigação e Drenagem) - Centro de Tecnologia e Recursos Naturais, Universidade Federal de Campina Grande, Campina Grande, 2014.

UNGARO, M. R. G.; CASTRO, C. de; FARIAS, J. R. B.; BARNI, N. A.; RAMOS, N. P.; SENTELHAS, P. C. GIRASSOL. In: MONTEIRO, J. E. B. A. (Org.). Agrometeorologia dos cultivos: o fator meteorológico na produção agrícola. 1, ed. Brasília, DF: INMET InfoAgro - Brasil, 2009. v.1, p. 203-222.

VRÂNCEANU, A. V. El girassol. Madri: Editora Mundi Prensa, 1977. 375p.

WARRICK, A. W.; NIELSEN, D. R. Spatial variability of soil physical properties in the field. In: HILLEL, D. (Ed.). Applications of soil physics. New York: Academic, 1980. Cap.2, p.319-344. 